In Dr Dunlop's Table I she omits Ellis \& Mellsop's (1985) criterion (C): "The other person had been the first to fall in love". Had this been applied, it would perhaps have been made clear that neither patient believed the object to be in love with her.

This diagnostic confusion stems from ambiguous usage of the term 'erotomania' to include a wide variety of types of pathological attachment behaviour. It is sometimes taken to indicate delusional love by the patient for another person, although in the de Clérambault syndrome the belief is of a love which is in precisely the opposite direction, i.e. from the object to the subject.

Enoch \& Trethowan (1979) remarked on the importance of distinguishing erotomania from everyday infatuation, normal passion, and nymphomania on the one hand, and paranoid schizophrenia on the other, but in the absence of clear definitions it becomes impossible to make these distinctions. Seeman (1978) pointed out that there is much overlap in the literature as to what is meant by the terms phantom lover syndrome, erotomania, and de Clérambault's syndrome. The resulting uncertainty is amply demonstrated in Ellis \& Mellsop's (1985) review of 58 cases, supposedly of de Clérambault's syndrome, of which only 11 (19\%) fulfilled the 'fundamental postulate' criteria (A, B, C, and D) which they adopted.

Cherry Knowle Hospital

Simon EMINSON

Ryhope, Sunderland

Tyne \& Wear SR2 ONB

TIM GiLleTt

St Nicholas Hospital

Gosforth

Newcastle

Roferences

Ellis, P. \& Mellsop, G. (1985) De Clérambault's syndrome-a nosological entity? British Journal of Psychiatry, 146, 90-95.

ENOCH, M. D. \& TRETHOWAN, W. H. (1979) Uncommon Psychiatric Syndromes (2nd edn). Bristol: John Wright.

LOVETt Doust, J. W. \& CHRiste, H. (1978) The pathology of love; some clinical variants of de Clérambault's syndrome. Social Science and Medicine, 12, 99-106.

SEEman, M. V. (1978) Delusional loving. Archives of General Psychiatry, 35, 1265-1267.

Signer, S. F. \& Cummongs, J. L. (1987) De Clérambault's syndrome in organic affective disorder. British Journal of Psychiatry, 151, 404-407.

\section{Post-traumatic stress disorder}

SIR: McFarlane's account of a bushfire (Journal, February 1989, 154, 221-228), while elegant in its methodology, is perhaps not capable of generalisation to post-traumatic stress disorder (PTSD) as a whole. He points out that most of the recent litera- ture focuses on Vietnam veterans and victims of disaster. These groups, however, differ significantly from Dr McFarlane's. Vietnam veterans were an unmotivated, socially disadvantaged group of draftees who were hardly prepared for what they faced, and victims of a disaster are a more heterogeneous group and are, by definition, completely unprepared for the trauma they experience. Dr McFarlane describes his group as large, trained and volunteer. They were recruited into the traumatic event after it started, were well motivated, and possibly had previous experience. It thus, by definition, lacked the element of surprise and unfamiliarity experienced by the other PTSD groups examined.

It may well be that this element of unpreparedness would account for the development of PTSD in some sufferers.

\section{Reaside Clinic \\ Bristol Road South \\ Rubery, Rednal \\ Birmingham B45 9BE}

\section{Neuronal misconceptions}

SiR: Goodman (Journal, March 1989, 154, 292-299) has set himself the difficult task of suggesting that anomalous neural connections underlie some psychiatric disorders. He has commendably suggested tests for his hypothesis. Nevertheless, it suffers from inherent difficulties. Firstly, it incorporates a two-stage pathogenesis: a primary lesion (e.g. brain damage) followed by maladaptive neuronal repair. The dual abnormalities would be more difficult to test in the clinical setting than more simplistic explanations, such as 'neuro excess' theories. Secondly, his attempts to explain a range of psychiatric abnormalities on the basis of misconnections have forced him to make simplistic generalisations, e.g. the dichotomisation between focal and diffuse misconnections, and their likely consequences. If, as he implies, abnormal (and by inference, random) misconnections lead to behavioural abnormalities, it is unlikely that such abnormalities take the form of consistent syndromes. Finally, a misconnection theory need not exclude other hypotheses. Indeed, 'misconnections' could lead to 'neuroexcess' or 'neurodeficiency'.

The relationship between temporal lobe epilepsy (TLE) and schizophrenia illustrates the difficulty of proving or disproving hypotheses of the sort proposed by Dr Goodman. While TLE has been associated with a number of psychiatric states (Vasquez, 1952), its link with schizophrenia has been debated (Small et al, 1986). Dr Goodman focuses on the increased prevalence of schizophrenia among 